\title{
Study on optimization of thermal spinning process of accumulator shell
}

\author{
Bin $\mathrm{Li}^{1,2}$, Yunan $\mathrm{Li}^{1,2}$, Peihao Zhu ${ }^{1,2, *}$, Wenpeng $\mathrm{Ma}^{1,2}$, Yinhong Xiao ${ }^{1,2}$, and Xiang $\mathrm{Li}^{1,2}$ \\ 1 Tianjin Key Laboratory for Advanced Mechatronic System Design and Intelligent Control, School of Mechanical Engineering, \\ Tianjin University of Technology, Tianjin 300384, PR China \\ ${ }^{2}$ National Demonstration Center for Experimental Mechanical and Electrical Engineering Education, Tianjin University of \\ Technology, Tianjin, PR China
}

Received: 18 May 2019 / Accepted: 15 November 2019

\begin{abstract}
In view of the shortcomings of the existing hot spinning process technology of the accumulator shell, a method for optimizing the multi-spinning process parameters is proposed. The Johnson-Cook constitutive model of the accumulator shell material - 34CrMo4 alloy steel - was established with its parameters obtained experimentally. The finite element simulation was carried out for the hot spinning and closing process. Based on which, three parameters with the greatest influence on the spinning formation were studied: spinning temperature, spindle speed and friction coefficient. Combined with the central composite test, the response surface model and the mapping relationship between the three parameters and the maximum mises stress as well as the maximum wall thickness increment of the shell were established. The Pareto optimized solution set was obtained through multi-objective optimization. Under the condition of not affecting product quality, the optimized solution with low spinning temperature and high spindle speed is selected to reduce energy loss and improve work efficiency. The results indicate that the optimized process is experimentally verified to reduce the process temperature by nearly $30^{\circ} \mathrm{C}$, and the efficiency is increased by $25 \%$.
\end{abstract}

Keywords: Accumulator / hot spinning technology / finite element / response surface / multi-objective optimization

\section{Introduction}

The accumulator is an energy storage device in hydraulic and pneumatic systems that stores or releases the compressive energy to ensure that the entire system is under normal pressure. The shell of the accumulator is an important part, and its manufacturing process is especially important to ensure the stability of the system transmission $[1,2]$. Therefore, it is of great significance to study the hot spinning process of the shell for its preparation. At present, the processing method of the accumulator shell is usually welding. However, there are obvious processing defects in it because stress concentration and cracks often occur at the welding points [3,4], which causes the accumulator to be scrapped $[5,6]$. Compared with the traditional welding process, the spinning process can prepare a seamless accumulator, which fundamentally avoids the processing defects caused by traditional processing method, improves the accumulator quality

\footnotetext{
* e-mail: zhupeihao_gp@163.com
}

and reduces the rejection rate and the processing cost $[7,8]$. The hot spinning process of the accumulator shell mentioned above is a high-energy process. Due to the current unreasonable process parameters, the effective energy conversion ratio is not high, and most of the energy is lost in the form of heat energy [9-11]. Therefore, optimization of the parameters of the hot spinning process for the accumulator shell is of vital importance for energy saving and the emission reduction.

At present, hot spinning processing has broad application prospects in the accumulator shell manufacturing industry due to the advantages of good metal deformation conditions, high material utilization rate, and significant product performance $[12,13]$. Although the hot spinning process has many advantages, there are still processing defects and deficiencies due to improper process parameters, such as peeling, corrugation, cracks, pinch instability and insufficient surface accuracy that may occur during spinning [14,15]. Many scholars at home and abroad have studied the improvement of spinning process parameters in response to the above problems. Some scholars optimize the spinning process parameters by the optimization 
algorithms. For example, Zhu [16] transformed multiobjective optimization into single-objective optimization through genetic algorithm, and finally found the optimal parameters to improve the safety of the accumulator. Hashemi Abbas et al. [17] used an adaptive optimization algorithm combined with fuzzy logic control and annealing optimization algorithm to find the optimal pressure load curve to prevent wrinkling of the shell casing during spinning contraction. Yoon et al. [18] used genetic algorithms in the noise reduction study of accumulators to reduce noise while reducing the transmission loss of energy to high frequency vibration. In addition, many scholars use simulation software to analyze the dynamic model or numerical model of the accumulator, and optimize the model parameters to achieve the purpose of process parameter optimization. Chen et al. [19] established the dynamic model of accumulator and pipeline through AMESim software, and analyzed the relevant parameters affecting the characteristics of the accumulator, optimized the model, and finally optimized the parameters to improve the stability of the system. Lin et al. [20] studied the finite element model of the influence of staggered spinning parameters on the accuracy of parts. The optimization parameters were obtained based on finite element analysis, which improved the precision of machining. Li et al. [21] used the ABAQUS software to establish a three-dimensional model of the part in the forming method of simultaneous spinning to produce two conical parts. The processing parameters were determined by metal forming principle analysis. Sedighi et al. [22] studied the spinning manufacturing of aluminum conical tubes, using threedimensional dynamic explicit model to simulate and study the strain distribution in the track, and finally found that the hardness of the conical tubes increased significantly. Takahashia et al. [23] studied the spinning process of SUS409 tube, calculated the damage value of the fracture criterion and the position of the maximum damage value by establishing a three-dimensional finite element model, and determined the spinning condition without crack. Luo et al. [24] studied the spinning technology of large-component complex thin-walled shells used in aerospace, and proposed a composite spinning process combined with back rolls to establish roll-type spinning and multi-neck spinning. They simulated the influence of different spinning process parameters on the maximum equivalent stress as well as maximum ellipticity of the sample with the finite element model of press forming, and determined the back roller spinning process parameters. Xue et al. [25] carried out nonlinear finite element simulation on the neck-spinning process, and studied the internal and external stress distribution of the pipeline deformation zone during the multi-pass shrinkage process. Zhanga [26] proposed a process to optimize the spinning compression port, which reversed the flow direction of the material and the direction of the spinning roller, and found that the internal surface precision was significantly improved. Roy et al. [27] used the experimental-numerical method to carry out the intermittent spinning test at room temperature on the 6061-0 aluminum alloy gas cylinder, and established a numerical simulation model to obtain the effect of spinning roller path on tube shape and thickness variation.
However, these studies have their shortcomings. Firstly, they only considered the influence of the spinning process on the quality parameters of the processed products, while ignored that the hot spinning process itself is a highly energy-intensive process and reducing the manufacturing costs is also a strong desire of manufacturers which should ensure energy-saving manufacturing and avoid the defects of spinning processing. Secondly, a number of process parameters have an effect on the spin forming. Considering the influence factors of the spinning roller path alone, optimizing the spinning roller path is not enough to characterize the optimization of the entire hot spinning process. Finally, the accurate numerical model of the accumulator material was not tested. It may result in an optimization result that is not meaningful to actual production guidance. Therefore, this paper makes a Hopkinson pressure bar experiment to accurately determine the constitutive model of the material for the accumulator material. For the problem of multiple spinning process parameters, the response surface-based central composite test [28] is used to determine the key influence parameters, and then apply multi-objective optimization algorithm for process parameter optimization. Under the premise of accurate modeling, the parameters are optimized for the high energy consumption in production and the complexity of multi-parameter problems, which reflects the novelty of this research.

In view of the high energy consumption and low production efficiency, which is common in the hot spinning process of accumulator shell [29,30], the process parameters need to be optimized to achieve the purpose of energysaving manufacturing without changing the accumulator quality. According to the above optimization objectives, an optimization method of accumulator spinning process parameters is proposed, which includes the following procedures: establishing the constitutive model of the accumulator shell material and the finite element model of the neck-spinning, analyzing the response surface relationship between parameters, and optimizing the process parameter.

\section{Materials and methods}

In this section, the method of establishing the JohnsonCook constitutive model of the material of the accumulator casing 34CrMo4 alloy steel, the process of using the obtained model to make the finite element analysis of the neck-spinning, the analysis method of the optimized parameters and the experimental design of the optimized parameters are introduced.

\subsection{Johnson-Cook constitutive model of $34 \mathrm{CrMo} 4$ alloy steel}

During the process of neck-spinning the accumulator shell, the sample material is often subjected to elastic deformation, large deformation and large strain rate at high temperature. Therefore, Jonson-Cook constitutive model $[31,32]$ is adopted to consider the influence of various factors (strain, strain rate, thermal softening) on the 
hardening stress of the sample material. The Jonson-Cook constitutive model formula [33] is as follows:

$$
\sigma=\left(A+B \varepsilon_{P}^{n}\right)\left(1+C \ln \frac{\dot{\varepsilon}}{\dot{\varepsilon}_{0}}\right)\left[1-\left(\frac{T-T_{0}}{T_{\text {melt }}-T_{0}}\right)^{m}\right]
$$

where, $A$ is the yield strength under quasi-static conditions, $B$ is the strain hardening parameter, $\varepsilon_{\mathrm{P}}$ is the equivalent plastic strain, $n$ is the hardening index, $C$ is the strain rate strengthening parameter, $\dot{\varepsilon}$ is the equivalent plastic strain rate, $\dot{\varepsilon}_{0}$ is the reference strain rate of the material, $T_{0}$ is the room temperature, usually $25^{\circ} \mathrm{C}, T_{\text {melt }}$ is the melting point of the material; $m$ is the thermal softening parameter.

To determine the constitutive model of the $34 \mathrm{CrMo} 4$ alloy steel, it is necessary to determine $A, B, C, n, m$ in formula (1). At room temperature and quasi-static, the Jonson-Cook constitutive formula (1) can be rewritten into formula (2), and the formula (2) can be rewritten as formula (3) by the following formula:

$$
\begin{gathered}
\bar{\sigma}=A+B \bar{\varepsilon}_{P}^{n} \\
\ln (\bar{\sigma}-A)=n \ln \bar{\varepsilon}_{p}+\ln B .
\end{gathered}
$$

It can be seen from formula (3) that the values of $A, B$ and $n$ in the constitutive model can be obtained by experiments and data analysis under static conditions. In order to obtain the quasi-static mechanical properties of the $34 \mathrm{CrMo} 4$ alloy steel, experiment is carried out on the CSS electronic universal testing machine. The model of the machine is WEW-300B manufactured by Haocheng Technology Co., Ltd., and the test used a cylindrical sample with a diameter of $10 \mathrm{~mm}$ and a height of $5 \mathrm{~mm}$. The experiment is carried out at room temperature $\left(20^{\circ} \mathrm{C}\right)$, and according to the national standard GB/T7314-2017 "Metal material compression test method at room temperature". A is the initial yield strength of the material at room temperature and quasi-static. $A$ can be determined by the test. The strain and stress values of the material obtained in the experiment can be used to obtain a fitting curve. The slope of the fitted curve is $n$, the intersection with the $y$-axis is $\ln B$, from which parameters $B$ and $n$ can be obtained.

To determine the parameters $C$ and $m$ in the constitutive model, the dynamic mechanical test must be carried out on the basis of the static parameters. The dynamic mechanical performance test is carried out with the Hopkinson pressure bar device. The device is operated by Beijing Dexing Technology Co., Ltd., China. The company's production model is ALT1000. The stress-strain curve of the material at different temperatures and strain rates is measured by the device. Considering the mechanical properties of $34 \mathrm{CrMo} 4$ alloy steel, the cutting temperature and the configuration of Hopkinson pressure bar experimental device, it is determined that the temperature range of the design test is from $950{ }^{\circ} \mathrm{C}$ to $1150^{\circ} \mathrm{C}$, and the strain rate is from $0.1 \mathrm{~s}^{-1}$ to $6.0 \mathrm{~s}^{-1}$.

The schematic of the Hopkinson pressure bar experimental device is pushing the bullet in the gas chamber, the speed measuring system can measure the speed of the bullet, and the bullet impacts the input rod through the force transmission to compress the test specimen and finally to the transmission rod. The strain measurement recording system records the strain gauge signal [34,35].

According to the incident wave, reflected wave and transmitted wave measured by the experimental device, the stress wave theory can be used to determine the values of strain, strain rate and stress from the formulas (4)-(6).

$$
\begin{gathered}
\varepsilon=-\frac{2 C_{0}}{L_{0}} \int_{0}^{t} \varepsilon_{i} d \tau \\
\dot{\varepsilon}=\frac{2 C_{0}}{L_{0}} \varepsilon_{r} \\
\sigma=\frac{E A}{A_{s}} \varepsilon_{e}
\end{gathered}
$$

where, $E$ is the Young's modulus, $A$ is the cross-sectional area, $C_{0}$ is the elastic wave velocity, $L_{0}$ is the initial length of the sample, $A_{\mathrm{s}}$ is the cross-sectional area of the sample, $\varepsilon_{\mathrm{i}}$ is the incident strain wave, $\varepsilon_{\mathrm{r}}$ is the reflected strain wave, $\varepsilon_{\mathrm{e}}$ is the transmission Strain wave.

In the case of different strain rates at the same temperature, the constitutive model formula of the material can be rewritten as formula (7) as follows:

$$
\frac{\bar{\sigma}}{A+B \bar{\varepsilon}_{\mathrm{P}}^{n}}-1=C \ln \dot{\varepsilon}^{*}
$$

The stress-strain relationship with the same temperature and different strain rate can be obtained by the Hopkinson pressure bar experiment. The formula (7) can be used to obtain the fitting curve, where $C$ is the slope of the fitting function.

In the case of different strain rates at different temperatures, the constitutive formula of the material can be rewritten as formula (8) as follows:

$$
\ln \left[\frac{\left(A+B \bar{\varepsilon}_{0}^{p n}\right)-\sigma}{A+B \bar{\varepsilon}_{0}^{p n}}\right]=m \ln T^{*}
$$

The stress-strain relationship with the same strain rate and different temperature can be obtained by the Hopkinson pressure bar experiment. The formula (8) can be used to obtain the fitting curve, where $m$ is the slope of the fitting function.

\subsection{Finite element model of spinning}

To establish of the finite element model of the accumulator neck-spinning, it is necessary to analyze the motion relationship between the spinning roller and the tube billet. In the actual accumulator spinning process, in order to process the work-piece that meets the design requirements, the spinning motion is decomposed into three motion modes as shown in Figure 1: axial velocity $\mathrm{V}$, its own rotational angular velocity $w_{1}$, oscillating motion $w_{2}$, and $w_{3}$ is the billet rotation speed. After the actual production analysis, the simulation motion parameters 


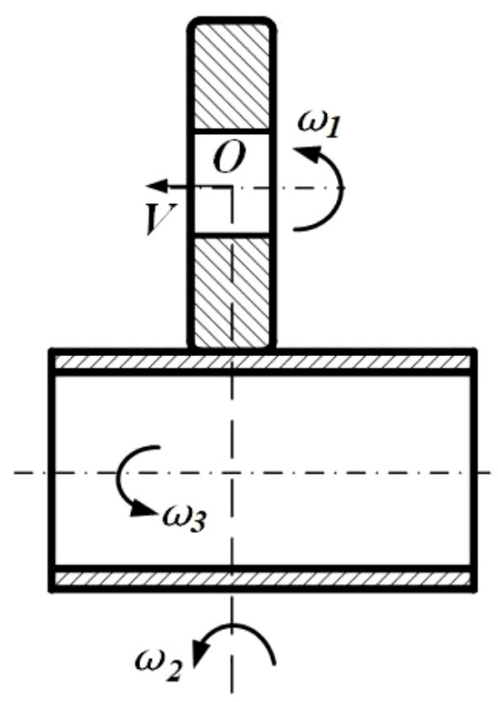

Fig. 1. Motion analysis.

Table 1. Parameters of spinning roller and tube billet.

\begin{tabular}{lll}
\hline Item & Parameters & Value \\
\hline $\begin{array}{l}\text { Spinning roller } \\
\text { parameters }\end{array}$ & Diameter & $600 \mathrm{~mm}$ \\
& Thickness & $130 \mathrm{~mm}$ \\
& Rounded corner & $10 \mathrm{~mm}$ \\
& Materials & $34 \mathrm{CrMo}$ alloy steels \\
& Spinning length & $400 \mathrm{~mm}$ \\
& Diameter & $600 \mathrm{~mm}$ \\
Tube billet & Wall thickness & $18 \mathrm{~mm}$ \\
parameters & & \\
& Density & $7850 \mathrm{~kg} / \mathrm{m}^{2}$ \\
& Elastic modulus & $15000 \mathrm{MPa}$ \\
& Poisson's ratio & 0.3 \\
\hline
\end{tabular}

were set as follows: the tube billet rotation speed is $200 \mathrm{r} / \mathrm{min}$, the spinning roller axial speed is $400 \mathrm{~mm} / \mathrm{min}$, the oscillating motion angular velocity is $0.3 \mathrm{rad} / \mathrm{s}$, and the spinning roller rotation speed is $150 \mathrm{r} / \mathrm{min}$.

In addition to the movement relationship between the spinning roller and the tube billet, various material parameters of the spinning roller and the tube billet are required. The material size parameters are obtained through actual measurement. The properties of the material are provided by Buccma Accumulator (Tianjin) Co., Ltd, and the material parameters are as shown in Table 1.

According to the parameters in Table 1, the threedimensional model of the spinning roller and tube billet, and the Johnson-cook model of the $34 \mathrm{CrMo} 4$ alloy steel established in the previous section are used to analyze the neck-spinning process of the accumulator with the finite element software ABAQUS [36], which is a famous engineering simulation of finite element software. The software is powerful enough to help users solve many

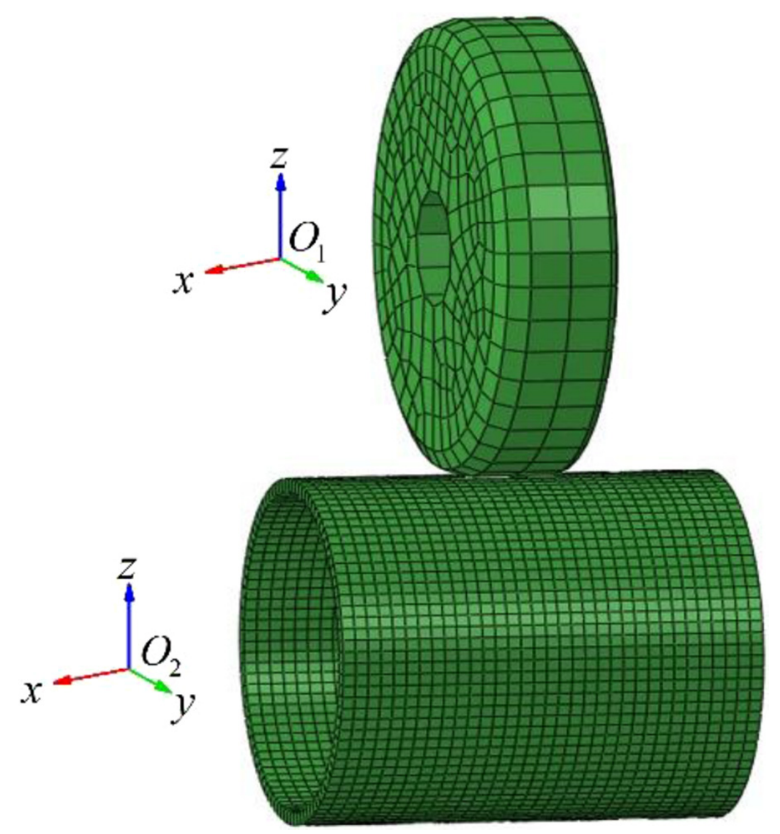

Fig. 2. Finite element model.

complex nonlinear problems, and has a rich library of cells that can simulate any geometry [37-39]. The Johnson-cook model is used to establish the stress-strain constitutive relationship of $34 \mathrm{CrMo} 4$ alloy steel. The model was meshed and the finite element model shown in Figure 2 was established.

The rigid joint in the ABAQUS is used to bind the clamping device to the tube billet, eliminating the rigid body displacement of both. At the beginning of the simulation, a constant rotation speed is applied to the tube billet, and the contact relationship between the spinning roller and tube billet is set. The contour of the spinning roller is always tangent to the outer contour line of the tube billet during the spinning process.

\subsection{Spin forming response surface model and optimization}

The spin forming quality of the accumulator shell is affected by the spinning temperature, friction coefficient and spindle speed. In order to construct the response surface model, these three parameters are used as the influencing parameters of the central composite design. The variation range of each parameter is measured by the actual accumulator spinning production process. The actual production process parameters are provided by Buccma Accumulator (Tianjin) Co., Ltd. The range of spinning temperature is from $950^{\circ} \mathrm{C}$ to $1150^{\circ} \mathrm{C}$, the range of friction coefficient is from 0.1 to 0.3 , the range of spindle speed varies is from 150 to $250 \mathrm{r} / \mathrm{min}$.

The central composite design method [28] needs to select two parameters that have important reference value for spin forming as the optimization target. In this study, the maximum stress and wall thickness increment are selected as the target variables, and the central composite design parameters shown in Table 2 are obtained. 
Table 2. Test parameters of response surface model.

\begin{tabular}{llllll}
\hline No. & $\begin{array}{l}\text { The spinning } \\
\text { temperature } x_{1}\left({ }^{\circ} \mathrm{C}\right)\end{array}$ & $\begin{array}{l}\text { Friction } \\
\text { coefficient } x_{2}\end{array}$ & $\begin{array}{l}\text { Main spindle } \\
\text { speed } x_{3}(\mathrm{r} / \mathrm{min})\end{array}$ & $\begin{array}{l}\text { Maximum } \\
\text { stress } y_{1}(\mathrm{MPa})\end{array}$ & $\begin{array}{l}\text { Maximum thickness } \\
\text { increment } y_{2}(\mathrm{~mm})\end{array}$ \\
\hline 1 & 1150 & 0.20 & 250 & 290.6 & 4.6 \\
2 & 1050 & 0.30 & 250 & 271.6 & 5.1 \\
3 & 1150 & 0.30 & 200 & 274.2 & 4.2 \\
4 & 1050 & 0.20 & 150 & 282.8 & 4.5 \\
5 & 1050 & 0.20 & 200 & 282.8 & 4.5 \\
6 & 950 & 0.20 & 150 & 317.7 & 5.4 \\
7 & 1050 & 0.10 & 250 & 304.2 & 4.0 \\
8 & 950 & 0.20 & 250 & 321.3 & 5.5 \\
9 & 950 & 0.30 & 200 & 308.7 & 6.0 \\
10 & 950 & 0.10 & 200 & 333.4 & 5.1 \\
\hline
\end{tabular}

In this paper, the response surface method is used to establish the mapping relationship between the maximum stress, thickness increment and parameters. There are two commonly used approximate models in the response surface method: the first-order response surface model and the second-order response surface model. Because of the nonlinear relationship between the maximum stress, the thickness increment and the three influencing parameters, the first-order response surface model cannot satisfy the regression effect. Therefore, this paper adopts secondorder response surface model to establish the spin-sleeve model of the accumulator shell. The second-order response surface model expression $[40,41]$ is:

$$
\widehat{y}=\alpha_{0}+\sum_{i=1}^{N} \alpha_{i} x_{i}+\sum_{j=1}^{N} \alpha_{j} x_{j}^{2}+\sum_{i j(i<j)}^{N} \alpha_{i j} x_{i} x_{j}
$$

where, $\widehat{y}$ is the response predicted by the approximate model, $x$ is the design variable, $N$ is the number of variables, $\alpha$ is the undetermined coefficient [42], which can be determined by formula (10).

$$
\alpha=\left(X^{T} X\right)^{-1} X^{T} y
$$

where, $X$ is the experimental sample point matrix, $X^{\mathrm{T}}$ is the transposed matrix of $x, y$ is experimental observation vector.

In order to obtain the mapping relationship, the secondorder response surface linear regression can be performed with variables in Table 2 by using the Design-Expert software. Design Expert [43-45] is feature-rich experimental analysis software developed by Statease. It provides drawing functions, which can draw function graphs, analysis graphs, coordinates, and chemical reaction graphs. The software can draw response surface analysis graphics. The graph can analyze the influence relationship between the maximum mises stress and each parameter, and the relationship between the thickness increment and each parameter.

The accumulator process optimization studied in this paper is a multi-objective optimization problem, which is the optimization design of two or more objectives at the same time. The optimal solution obtained by multiobjective optimization is the result of trade-offs among various goals. The optimal solution obtained may not be the optimal solution of a single goal, but it is the solution that makes each sub-goal reaches the optimal solution as far as possible. The NSGA-II algorithm enhances the ability of choosing solutions near the Pareto, which accelerate to obtain the optimal solution.

According to the obtained parametric formulas for multi-objective optimization, the problems to be studied are described in combination with the actual situation. Within the range of variation allowed by the independent variables $x_{1}, x_{2}$ and $x_{3}$, it is desirable to simultaneously obtain the minimum value of the maximum misses stress $y_{1}$ and the minimum value of the thickness increment $y_{2}$.

Isight software is used for multi-objective optimization. Isight $[46,47]$ is engineering design development system software developed by the Ph.D. of the Massachusetts Institute of Technology. It is recognized by the world as a "software robot" that integrates $\mathrm{CAD} / \mathrm{CAM} / \mathrm{CAE}$ and PDM systems. The regression formula and the initial values of the design variables $x_{1}, x_{2}$ and $x_{3}$ are input into the computer, the upper and lower limits of the variable are set, and the NSGA-II algorithm [48,49] is selected to solve all the solutions of Pareto.

\subsection{Experimentation}

The Isight software provides a set of optimal solutions for the actual accumulator spinning production. To verify the validity of the optimized spinning process parameters, experiment is performed on the spinning machine of the Buccma Accumulator Co., Ltd. The spinning machine model is YR-420, which is manufactured by Yongrun High Pressure Container (Taizhou) Co., Ltd., and is shown in Figure 3. This machine is used to produce the accumulator, and the residual stress of accumulator is compared between the former process and the optimized one to verify whether the optimized product qualifies or not.

In order to investigate whether the optimized process parameters improve the efficiency of the accumulator manufacturing, it is necessary to calculate the production efficiency, and calculate the time taken by the spinning roller 
to spin the tube billet once. The formula is as shown in formula (11). The efficiency calculation formula is shown in formula (12). It is determined that the feed ratio of the spinning roller is to be introduced. The feed ratio of the spinning roller is one spinning of the main spindle and the distance that the spinning roller moves. The formula is as shown in formula (13). The feed ratio is a very important parameter in the spinning forming process, and whether the value is selected properly directly affects the molding quality of the spinning product. According to Buccma Accumulator's years of experience in the manufacture of accumulators, the quality of the accumulator is best when the feed ratio $f$ is fixed at 2 .

$$
\begin{gathered}
t=\frac{l}{v} \\
\eta=\frac{t_{0}-t}{t_{0}} \\
f=\frac{v}{n}
\end{gathered}
$$

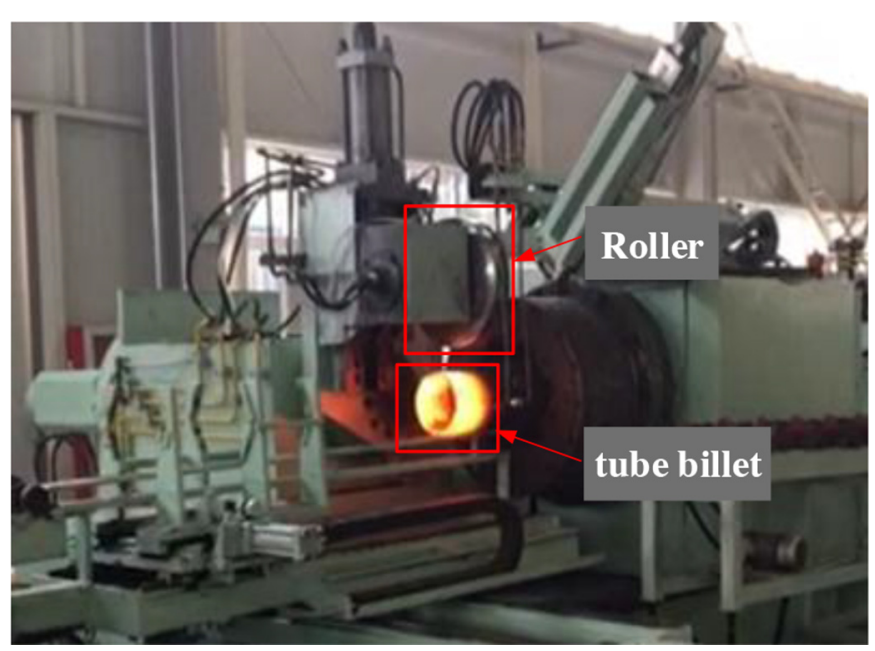

Fig. 3. Spinning machine.

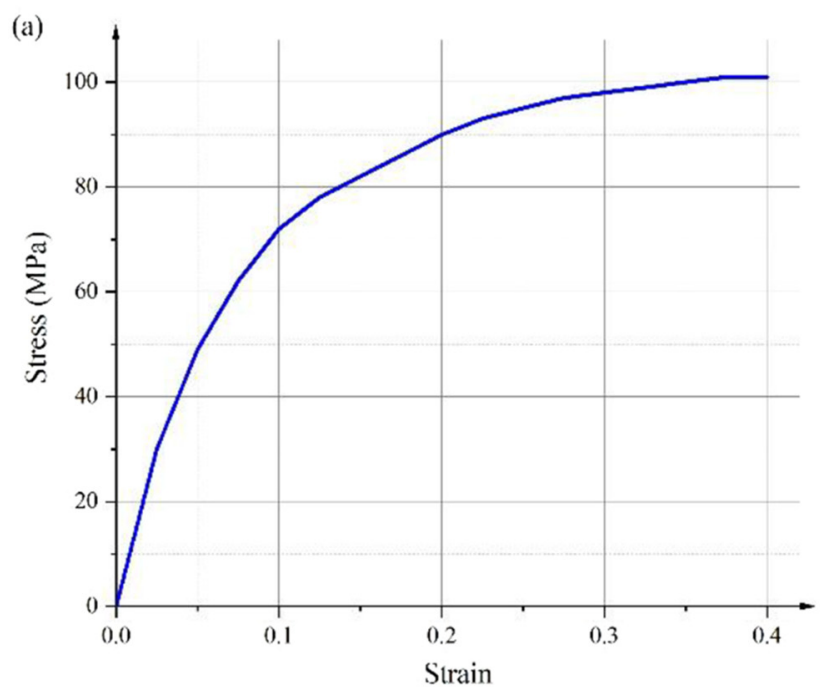

where, $f$ is the feed ratio of the spinning roller, $v$ is the feed speed of the spinning roller, $n$ is the spindle speed, $t_{0}$ is the time it takes for the spinning roller to spin once before optimization, and $\eta$ is the efficiency.

The formula for calculating the efficiency that can be derived from the above formulas (11)-(13) can be rewritten as formula (14).

$$
\eta=\frac{n-n_{0}}{n_{0}}
$$

In order to verify the effectiveness of the optimized process parameters, the residual stress of the spinning parts before and after optimization is analyzed by the Proto-LXRD X-ray residual stress analyzer [50], which is manufactured by Proto, Canada, and can detect residual stress at different positions of a part. By comparing the residual stresses at different positions of the accumulator before and after the optimization, it can be verified whether the accumulator manufactured is qualified after optimization.

\section{Results}

\subsection{Johnson-cook constitutive model}

The stress-strain curve of the $34 \mathrm{CrMo} 4$ alloy steel obtained by the CSS electronic universal testing machine is shown in Figure $4 \mathrm{a}$, according to the formula (3) and the stressstrain curve, the fitting curve can be obtained as shown in Figure $4 b$.

Therefore, the initial yield strength of the material can be obtained by static compression test: $A=824.6 \mathrm{MPa}$, and the parameters of the constitutive formula can be obtained according to the fitting curve shown in Figure 5b: $B=524 \mathrm{MPa}, n=0.71$.

The results obtained by the Hopkinson pressure bar experiment are shown in Figure 5. Figure 5a is the true stress-strain curve of the $34 \mathrm{CrMo} 4$ alloy steel with a hardness of $45 \mathrm{HRC}$ at room temperature and different

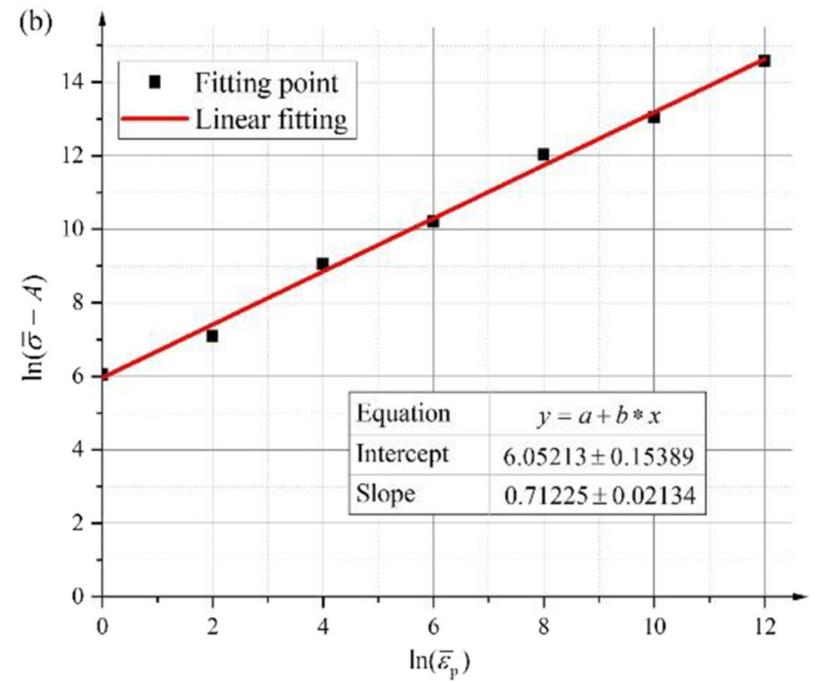

Fig. 4. Results of static compression test:(a) stress-strain curve and (b) fit curve of B and $n$. 

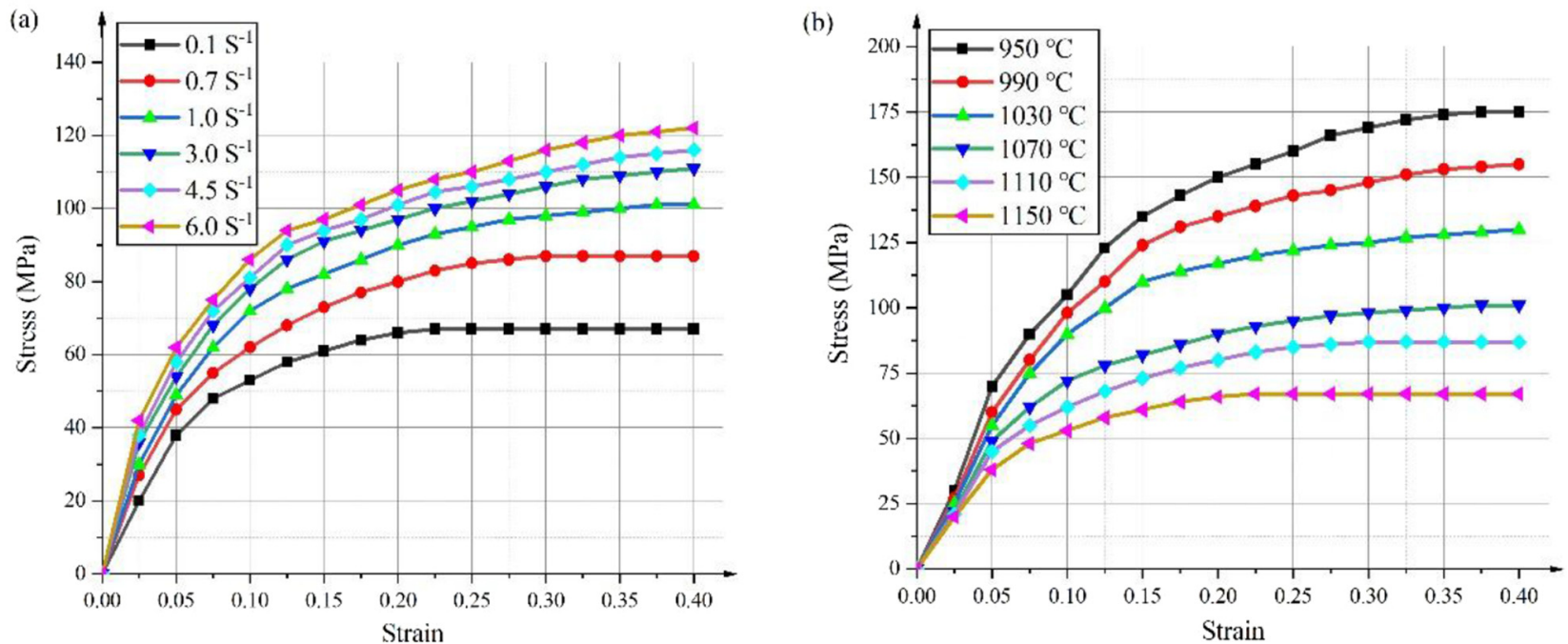

Fig. 5. Results of Hopkinson pressure bar experiment: (a) stress-strain curves at different strain rates and (b) stress-strain curves at different temperatures.
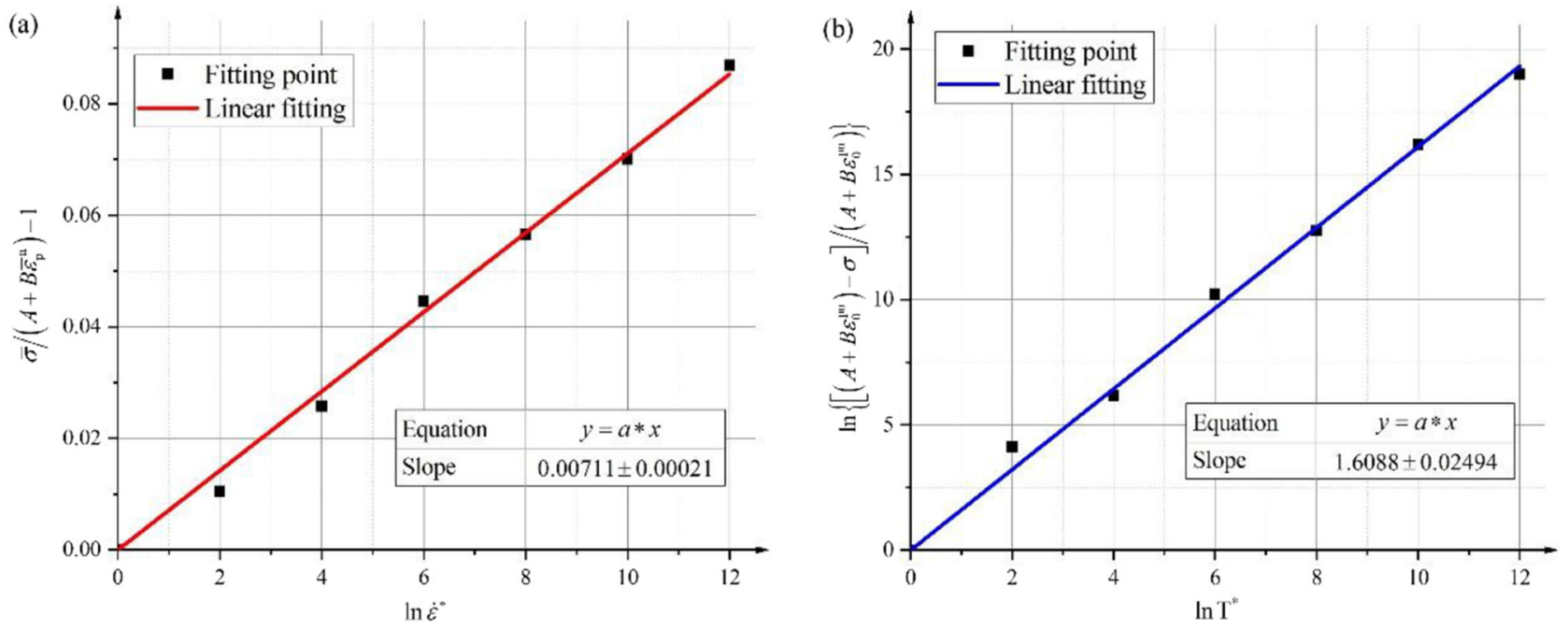

Fig. 6. Results of linear fitting: (a) fit curve of $\mathrm{C}$ and (b) fit curve of $\mathrm{m}$.

strain rate. Figure 5b is the stress-strain curve of $34 \mathrm{CrMo} 4$ alloy steel with a hardness of $45 \mathrm{HRC}$ at the same strain rate of $3.0 \mathrm{~s}^{-1}$ but different temperatures.

According to the experimental data of Figure 5 and the formulas (7) and (8), the fitting curves can be respectively obtained, as shown in Figure 6. Therefore, according to the fitting curve Figure $6 \mathrm{a}$ and $\mathrm{b}$, the parameters of the constitutive formula can be obtained: $C=0.0072, m=1.6$. Therefore, the Jonson-Cook constitutive model of $34 \mathrm{CrMo} 4$ alloy steel was finally determined:

$$
\begin{aligned}
\sigma= & \left(824.6+524 \varepsilon_{P}^{0.71}\right)\left(1+0.0072 \ln \frac{\dot{\varepsilon}}{\dot{\varepsilon}_{0}}\right) \\
& {\left[1-\left(\frac{T-T_{0}}{T_{\text {melt }}-T_{0}}\right)^{1.6}\right] . }
\end{aligned}
$$

\subsection{Finite element model}

The simulation results of the different states of the accumulator shell spin forming progress are shown in Figure 7, and Figure 7e is the equivalent stress curve of the bottle over time.

Figure 8 shows the strain simulation results. The strain increases with the forming progress. When the neckspinning is completed, the strain value reaches the maximum. It can also be seen from Figure 8e that when the roller spins the bottle mouth, the strain changes greatly.

\subsection{Response surface model and optimization}

The second-order response surface linear regression of independent variable $x_{1}, x_{2}, x_{3}$ and dependent variable $y_{1}$ in Table 2 was performed by the Design-Expert software 
(a)

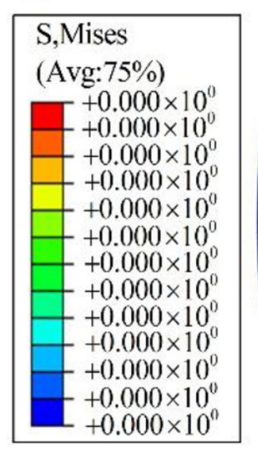

(c)

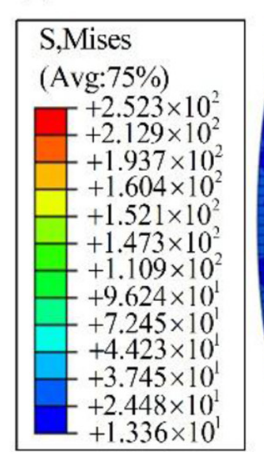

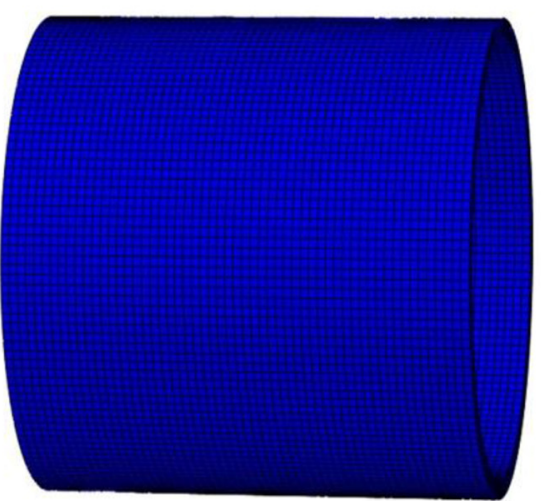

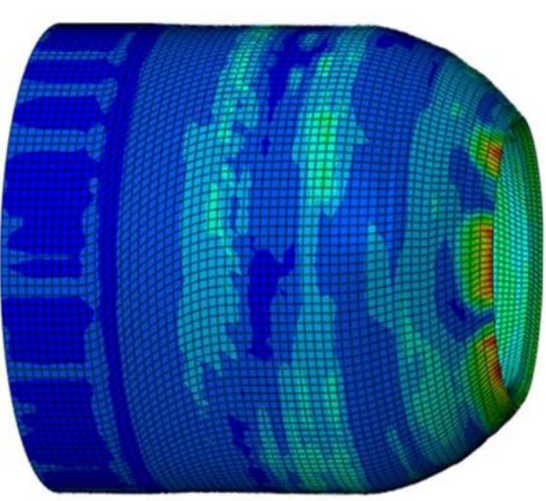

(b)
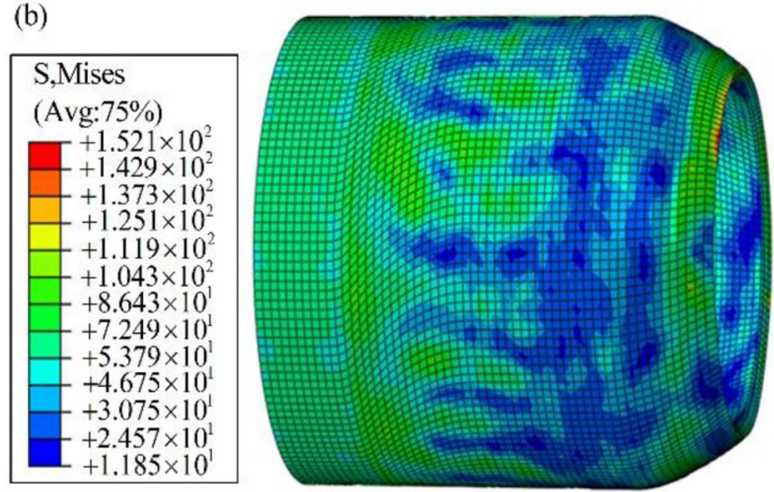

(d)
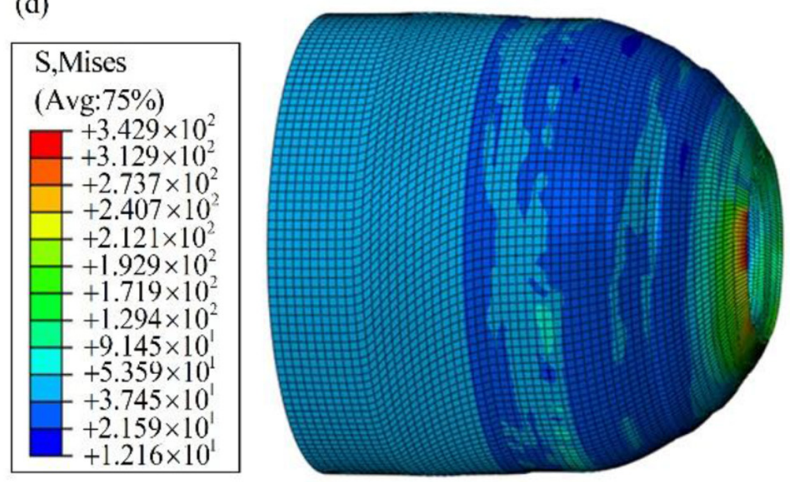

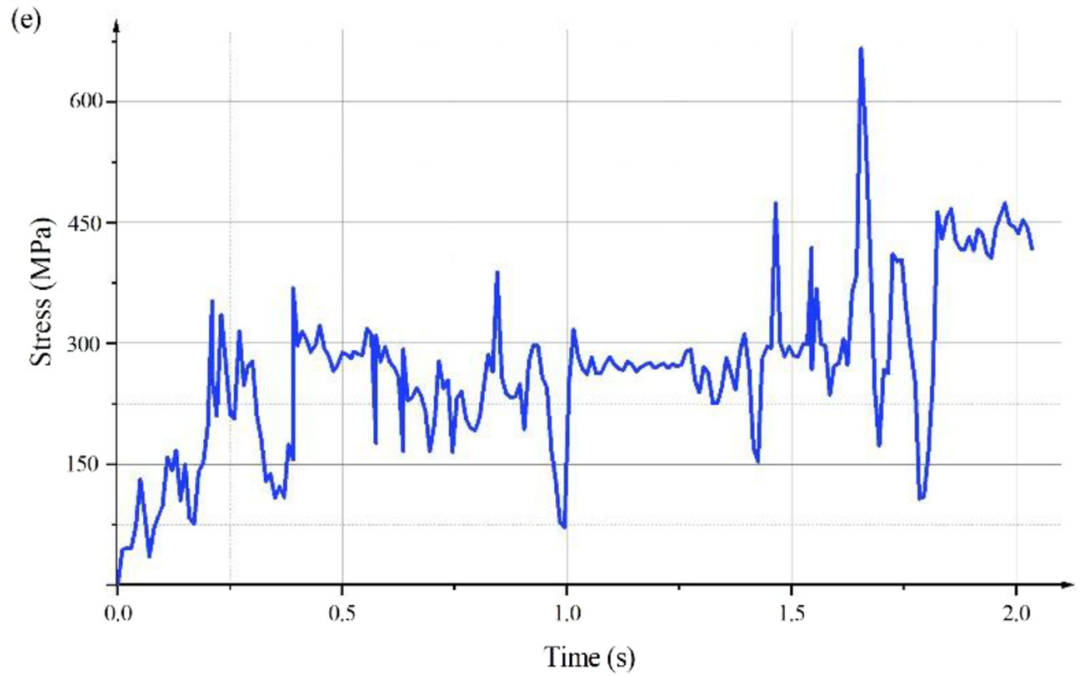

Fig. 7. Stress simulation results: (a) original state, (b) the first state, (c) the second state, (d) the third state and (e) the equivalent stress curve over time of the bottle neck.

package. The regression formula of the prediction model is as follows:

$$
\begin{gathered}
y_{1}=343.70-0.1 .65 x_{1}-2.64 x_{2}+2.09 x_{3} \\
-0.18 x_{1} x_{2}-1.77 x_{1} x_{3}+0.25 x_{2} x_{3} \\
+8.75 x_{1}^{2}-1.97 x_{2}^{2}-2.77 x_{3}^{2}
\end{gathered}
$$

A three-dimensional map composed of the maximum mises stress and the influencing parameters of the accumulator forming can directly reflect the influence of each variable on the response variable. The impact of the independent variable on the maximum mises stress is shown in Figure 9.

A second-order response surface linear regression was performed between the independent variables and dependent variable $y_{2}$ in Table 2 using the same method. The regression formula of the prediction model is as formula (17). The effect of the independent variable on the 
(a)

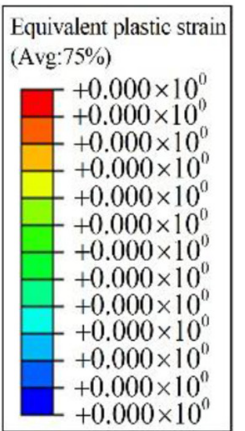

(c)

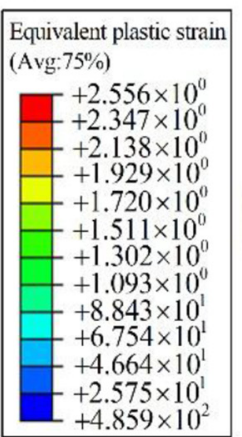

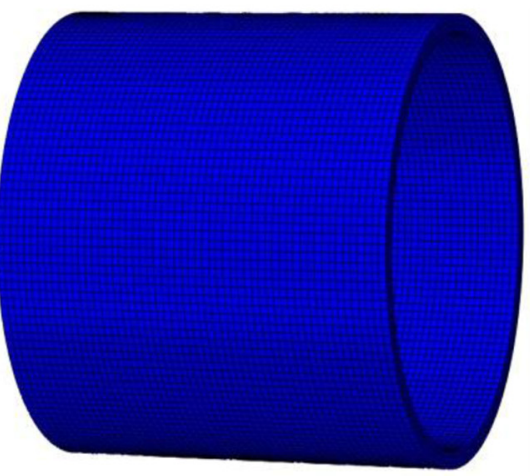

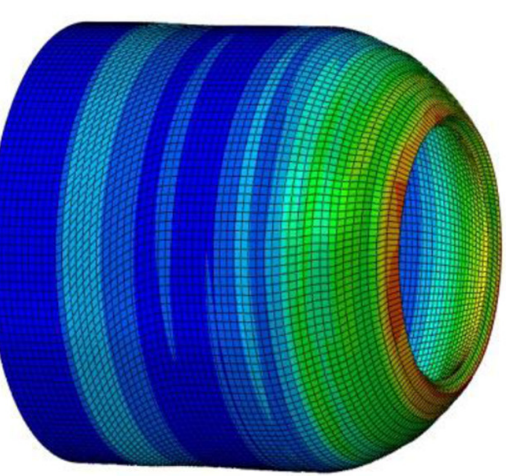

(b)
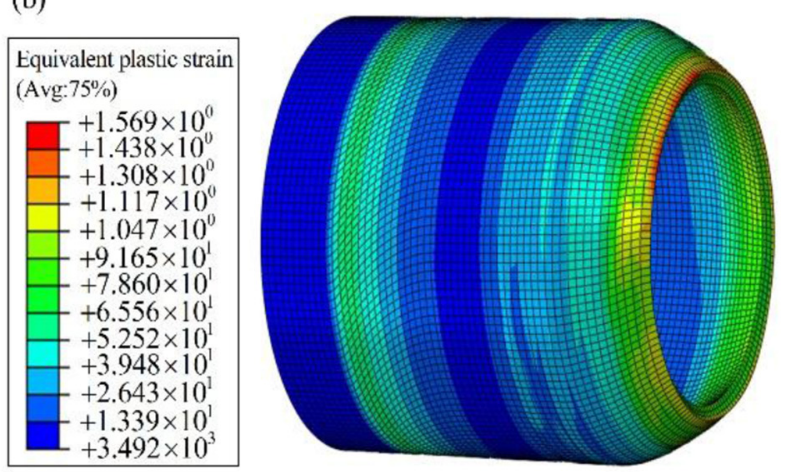

(d)
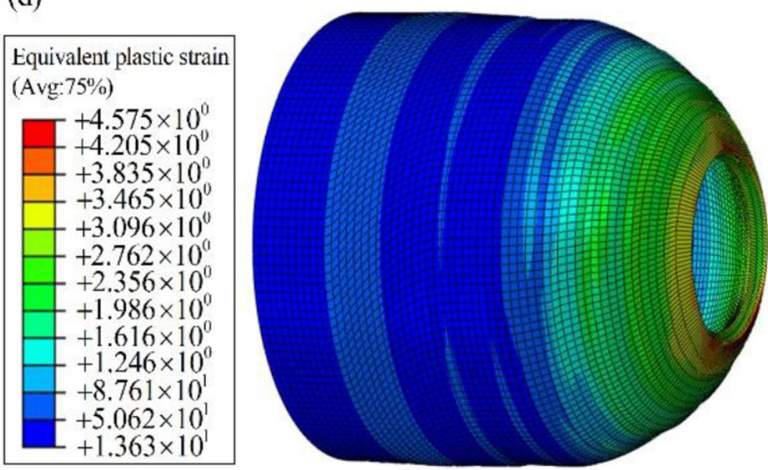

(e)

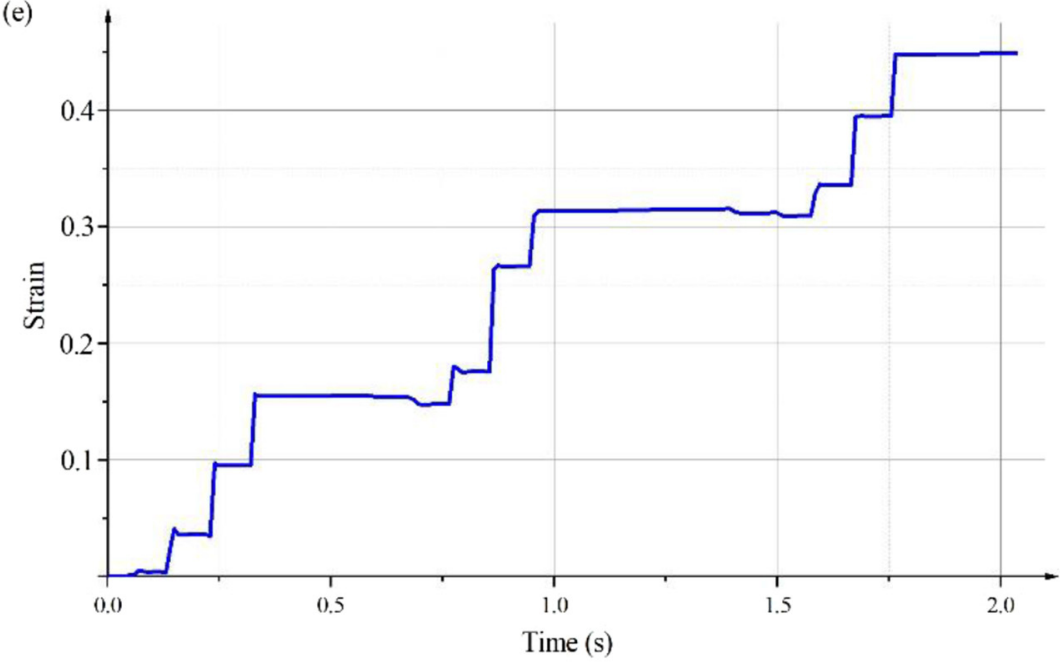

Fig. 8. Strain simulation results: (a) original state, (b) the first state, (c) the second state, (d) the third state and (e) the strain curve over time of the bottle neck.

thickness increment is shown in Figure 10.

$$
\begin{aligned}
y_{2} & =4.65-0.39 x_{1}+0.85 x_{2}-0.11 x_{3}-0.15 x_{1} x_{2} \\
& -0.15 x_{1} x_{3}+0.05 x_{2} x_{3}+0.49 x_{1}^{2}+1.7 \times 10^{-2} x_{2}^{2} \\
& +0.24 x_{3}^{2}
\end{aligned}
$$

Multi-objective optimization was performed by Isight software to obtain all the Pareto solutions. Part of the Pareto solutions is shown in Table 3. A scatter plot between the maximum misses stress $y_{1}$, the thickness increment $y_{2}$ and the independent variable can be observed in the Isight window, as shown in Figure 11. The highlighted point in the figure is the scatter point of the Pareto optimization solution on the coordinate axis. Figure 11b shows the distribution of the Pareto optimized solution set on the 3D coordinate axis.

By analyzing the distribution of the Pareto optimized solution set on the 3D coordinate axis, combined with the specific data given in Table 3 , it can be seen that the optimized solution set is mainly concentrated in some specific range, and it has important reference value for the optimization and design of target quantity. 

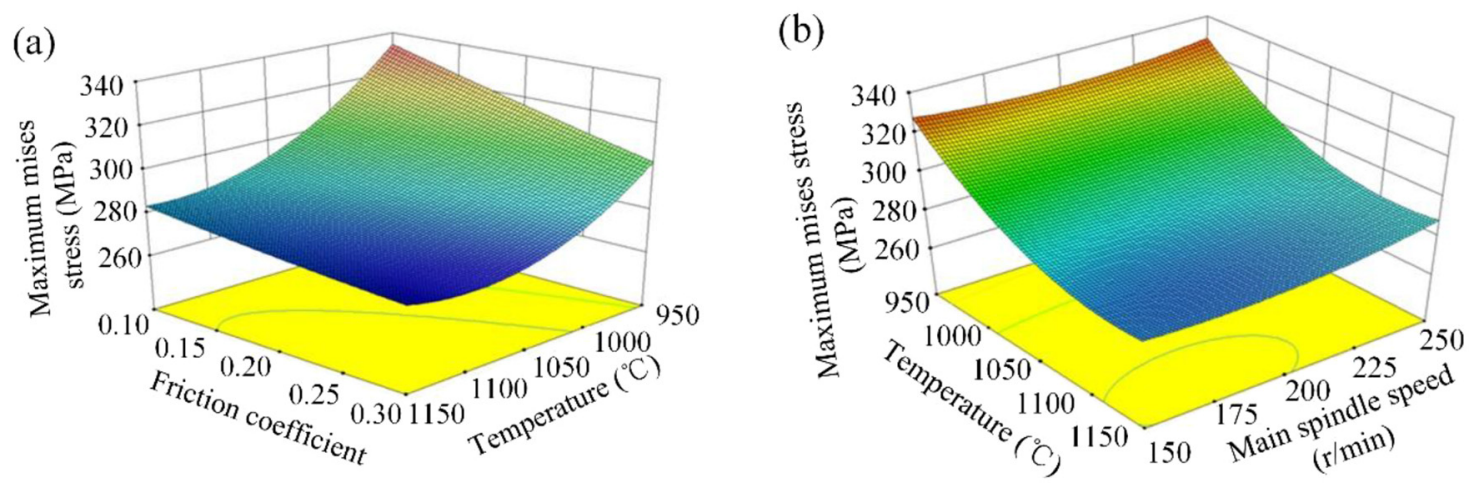

Fig. 9. (a) Influence of friction coefficient and temperature on maximum mises stress and (b) influence of temperature and spindle speed on the maximum mises stress.
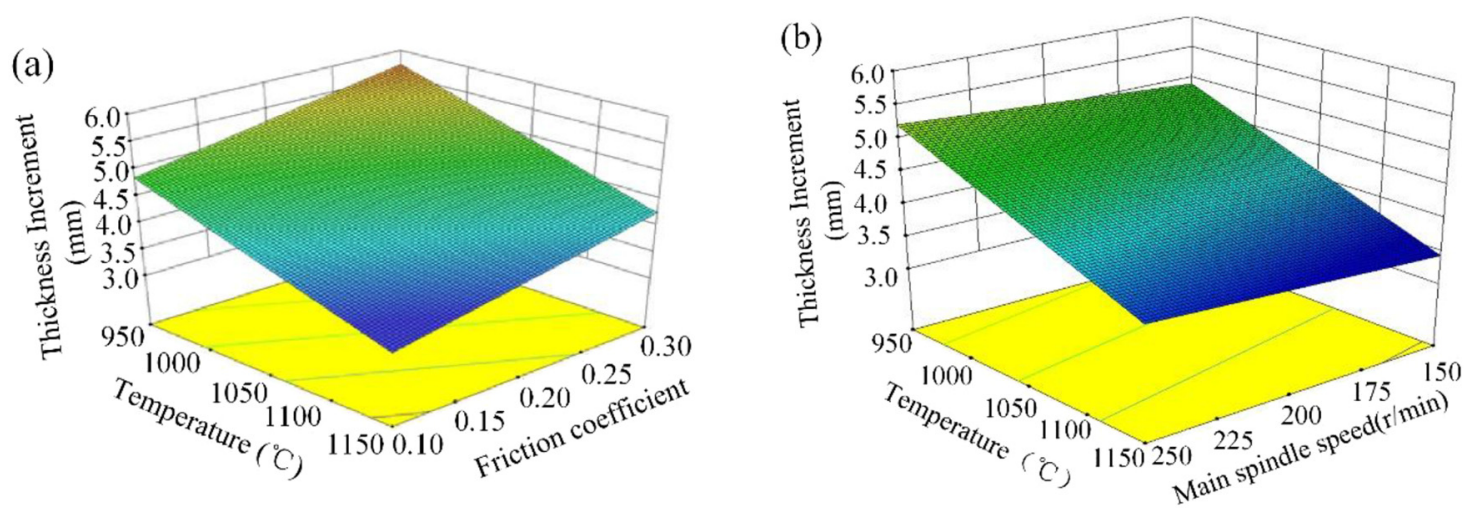

Fig. 10. (a) Influence of friction coefficient and temperature on thickness increment and (b) influence of temperature and friction coefficient on thickness increment.

Table 3. Part of the Pareto solutions.

\begin{tabular}{llllll}
\hline No. & $\begin{array}{l}\text { The spinning } \\
\text { temperature } x_{1}\left({ }^{\circ} \mathrm{C}\right)\end{array}$ & $\begin{array}{l}\text { Friction } \\
\text { coefficient } x_{2}\end{array}$ & $\begin{array}{l}\text { Main spindle } \\
\text { speed } x_{3}(\mathrm{r} / \mathrm{min})\end{array}$ & $\begin{array}{l}\text { Maximum } \\
\text { stress } y_{1}(\mathrm{MPa})\end{array}$ & $\begin{array}{l}\text { Maximum thickness } \\
\text { increment } y_{2}(\mathrm{~mm})\end{array}$ \\
\hline 1 & 969.91 & 0.239 & 148.65 & 310.5 & 4.39 \\
2 & 976.86 & 0.169 & 182.09 & 312.6 & 4.34 \\
3 & 1013.5 & 0.209 & 158.3 & 314.6 & 4.25 \\
4 & 1000.9 & 0.172 & 210.44 & 309.1 & 4.93 \\
5 & 1081.3 & 0.169 & 192.09 & 300.9 & 4.06 \\
6 & 1008.4 & 0.170 & 171.44 & 306.6 & 3.82 \\
7 & 1005.7 & 0.261 & 192.18 & 305.9 & 4.07 \\
8 & 1122.1 & 0.175 & 211.25 & 296.7 & 3.53 \\
9 & 1114.5 & 0.232 & 191.25 & 301.6 & 3.36 \\
10 & 1021.2 & 0.173 & 197.56 & 298.62 & 3.42 \\
\hline
\end{tabular}

\subsection{Verify experimental results}

The optimal solution provided by the Isight software in all optimization solutions is: spinning temperature $1021.2^{\circ} \mathrm{C}$, friction coefficient 0.173 , spindle speed $197.56 \mathrm{r} / \mathrm{min}$. Compared with the production process parameters (spinning temperature $1050^{\circ} \mathrm{C}$, spindle speed $150 \mathrm{r} / \mathrm{min}$ ) of Buccma Accumulator (Tianjin) Co., Ltd, the temperature is reduced by nearly $30^{\circ} \mathrm{C}$ and the spindle speed is increased by nearly $50 \mathrm{r} / \mathrm{min}$. This paper will verify the obtained optimal solution experimentally.

The optimal solution obtained above was taken as the process parameter and verified by experiments on the spinning machine of Buccma Accumulator (Tianjin) Co., Ltd. The tube billet has a diameter of $600 \mathrm{~mm}$ and a wall thickness of $18 \mathrm{~mm}$. After the spinning is completed, the 

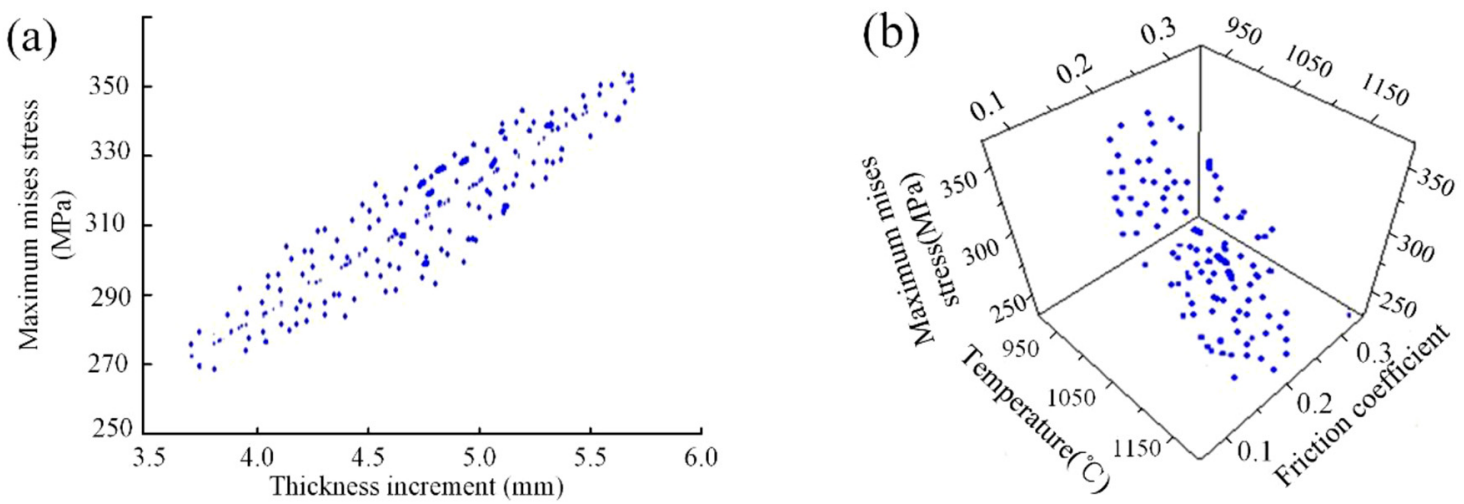

Fig. 11. Distribution of optimal solutions: (a) optimal solution distribution of maximum mises stress and thickness increment and (b) optimal solution distribution of stress, temperature and friction coefficient in 3D view.

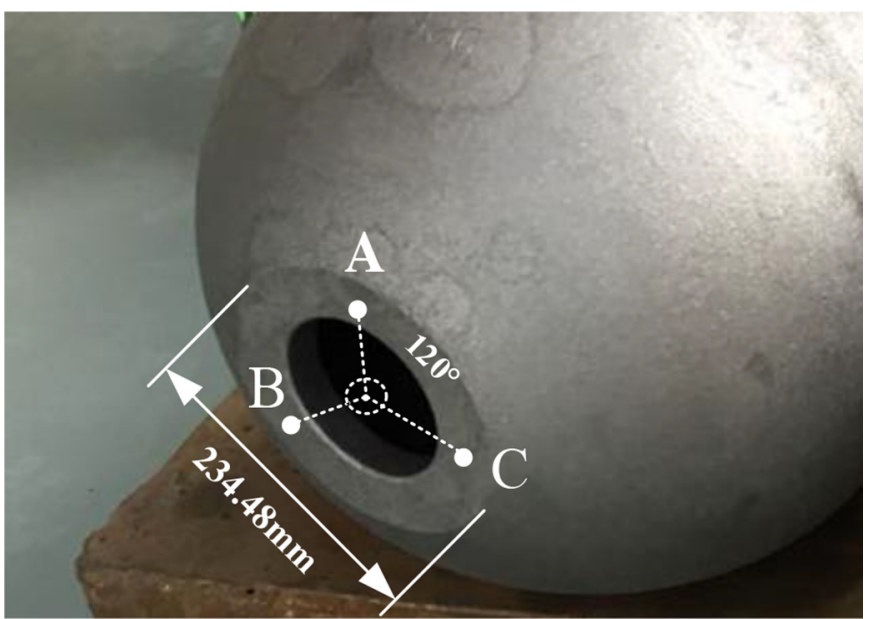

Fig. 12. Test point.

diameter of the bottle mouth is $234.48 \mathrm{~mm}$, while the diameter of the simulated test is $247.26 \mathrm{~mm}$, and the error is $5.45 \%$, within the error tolerance. The maximum thickness from experiment is $23.52 \mathrm{~mm}$, while it is $24.46 \mathrm{~mm}$ from simulation, and the error is $3.99 \%$, which is within the allowable range.

The residual stress of the accumulator shell was analyzed by a Proto-LXRD X-ray stress analyzer. Three points $\mathrm{A}, \mathrm{B}$, and $\mathrm{C}$ at the mouth of the bottle with intervals of 120 degree are selected as test points, as shown in Figure 12. The analysis results and simulation results before and after optimization are shown in Table 4. Except for the slightly larger error of point $\mathrm{C}$, the error of all other points is within the acceptable range, which proves that the above modeling is reliable. Comparing the residual stress values at the three points before and after optimization, it is found that the quality of the optimized accumulator is basically unchanged, which can ensure that the optimized process parameters have reference value for the actual production accumulator. The spindle speed is increased from $150 \mathrm{r} / \mathrm{min}$ to $200 \mathrm{r} / \mathrm{min}$ after optimization. Calculated by formula (14), the efficiency is also increased by $25 \%$.

\section{Discussion}

It can be seen from the simulation results in Figure 7 that the neck-spinning process is smooth. The second state has a significantly larger maximum equivalent stress than the first one, which is due to the smaller closing amount of the tube billet and the less stress generated in the first state. The third state has a smaller maximum equivalent stress increment than the second one, because the second state required spin pressure is the same as the third one. Shrinkage causes an equivalent stress to increase. It can also be seen from the equivalent stress curve of the bottle neck of Figure 7e that the stress is gradually increased, and the maximum stress during the spinning process is about $460 \mathrm{MPa}$. After the spinning is completed, the maximum mises stress is about $310 \mathrm{MPa}$. However, under the ultimate stress, no fracture occurred.

The response surface graphs of Figure 9 visually reflect the effects of temperature, friction coefficient, and spindle speed on the maximum mises stress. The maximum mises stress decreases as the spinning temperature increases, because the fluidity of the metal material increases as the temperature increases, thereby lowering the internal stress. As the friction coefficient increases gradually, the maximum mises stress increases, which are due to the decrease of the fluidity of the metal material according to the increase of the friction coefficient, and the internal stress is increased. The spindle speed has little effect on the mises stress.

The influence of the independent variable on the thickness increment can be seen from Figure 10. The increase of temperature will lead to the increase of material fluidity, so that the material in the stressed area is more prone to diffusion and the deformation of the wall thickness is more uniform when the spinning roller squeezes the tube billet. The increase of the friction coefficient leads to an increase in the friction between the spinning roller and the tube billet, so that the fluidity of material of the tube billet is lowered, and the material is difficult to be sufficiently diffused, and the local thickness of the tube billet is 
Table 4. Experimental and simulation results.

\begin{tabular}{lllll}
\hline Point & $\begin{array}{l}\text { Stress value before } \\
\text { optimization (MPa) }\end{array}$ & $\begin{array}{l}\text { Stress value after } \\
\text { optimization (MPa) }\end{array}$ & $\begin{array}{l}\text { Simulated } \\
\text { stress (MPa) }\end{array}$ & $\begin{array}{l}\text { Optimization and } \\
\text { simulation error }\end{array}$ \\
\hline A & 311.24 & 312.43 & 295.34 & $5.47 \%$ \\
B & 308.72 & 298.52 & 284.56 & $4.67 \%$ \\
C & 305.59 & 305.36 & 282.27 & $7.56 \%$ \\
\hline
\end{tabular}

increased. The spindle speed has little effect on the wall thickness, and as the spindle speed increases, the wall thickness increases slightly.

From the comparison between the finite element model of the neck-spinning and the actual data of the company's spinning machine in Table 4, it can be analyzed that, in actual working conditions, the temperature of the deformed region of the tube billet is not uniform with the heat loss and local heating of the supplemental heat device. However, the simulation temperature is constant, which causes errors between the experimental simulation and the actual machining. If we study the energy loss during the spinning process and the temperature distribution of the tube billet, modifying the model parameters will create a more accurate simulation model.

From the comparison of the residual stress values of the accumulator bottle mouth test points before and after optimization in Table 4, it can be seen that the residual stress value has a slight error, but the maximum error does not exceed $10 \mathrm{MPa}$. The error may be related to the selection of the testing point or the measurement error. Since the error is very small, it can be considered that the optimized process parameters do not affect the quality of the accumulator.

\section{Conclusions}

In this study, a method of finite element model analysis and multi-objective optimization for process parameter optimization was proposed. Firstly, the parameters of the Johnson-Cook constitutive model of 34CrMo4 alloy steel were obtained experimentally, and the constitutive model of the material was established. Secondly, based on the constitutive relationship, the finite element simulation of the hot neck-spinning of the accumulator shell was carried out, and combined with the central composite design, several process parameters that have great impacts on the forming were analyzed. Finally, for the multi-parameter optimization, this paper used the multi-objective optimization method to obtain the optimal combination of process parameters. And the hot spinning process experiment verified the validity of the optimal process parameters.

In the finite element simulation of the neck-spinning of the accumulator shell, the constitutive model of the accumulator casing material $34 \mathrm{CrMo} 4$ alloy steel was determined, which had a great effect on the accuracy of the simulation. It can be seen from Table 4 that the difference between the optimized simulation results and the experimental results was very small, and the maximum error in the test points does not exceed $8 \%$, which proved that the simulation accuracy of the neckspinning was high.

Under the premise of not affecting the quality of the product, the spinning temperature was reduced from the original $1050-1060{ }^{\circ} \mathrm{C}$ to $1020-1030{ }^{\circ} \mathrm{C}$, achieving the purpose of reducing energy loss. The spindle speed had been increased from the original $150 \mathrm{r} / \mathrm{min}$ to $200 \mathrm{r} / \mathrm{min}$, which had improved the production efficiency and improved efficiency by $25 \%$.

The authors gratefully acknowledge the support from the Belt and Road International Scientific and Technological Cooperation Demonstration Project (Grant No. 17PTYPHZ20060), the National Natural Science Foundation of China (Grant No. 61941305), the Tianjin Science and Technology Project (Grant No. 19YFFCYS00110), and the Natural Science Foundation of Tianjin of China (Grant No.18JCQNJC75000).

\section{Nomenclature}

A Yield strength under quasi-static conditions, formula (1)

A Cross-sectional area, formula (6)

$A_{\mathrm{S}} \quad$ Cross-sectional area of the sample

$B \quad$ Strain hardening parameter

$C \quad$ Strain rate strengthening parameter

$C_{0} \quad$ Elastic wave velocity

E Young's modulus

$f \quad$ Feed ratio of the spinning roller

$L_{0} \quad$ Initial length of the sample

$m$ Thermal softening parameter

$n \quad$ Hardening index, formula (1)

$n \quad$ Spindle speed, formula (13)

$N \quad$ Number of variables

$t_{0} \quad$ Time it takes for the spinning roller to spin once before optimization

$T_{0} \quad$ Room temperature, usually $25{ }^{\circ} \mathrm{C}$

$T_{\text {melt }}$ Melting point of the material

$v \quad$ Feed speed of the spinning roller

$V \quad$ Axial velocity

$w_{1} \quad$ Rotational angular velocity

$w_{2} \quad$ Oscillating motion

$w_{3} \quad$ Billet rotation speed

$x \quad$ Design variable

$x_{1} \quad$ Spinning temperature

$x_{2} \quad$ Friction coefficient

$x_{3} \quad$ Main spindle speed 
$X \quad$ Experimental sample point matrix

$X^{\mathrm{T}} \quad$ Transposed matrix of $x$

$y \quad$ Experimental observation vector

$y_{1} \quad$ Maximum stress

$y_{2} \quad$ Maximum thickness increment

$\widehat{y} \quad$ Response predicted by the approximate model

$\alpha \quad$ Undetermined coefficient

$\varepsilon_{\mathrm{P}} \quad$ Equivalent plastic strain

$\dot{\varepsilon} \quad$ Equivalent plastic strain rate

$\dot{\varepsilon}_{0} \quad$ Reference strain rate of the material

$\varepsilon_{\mathrm{i}} \quad$ Incident strain wave

$\varepsilon_{\mathrm{r}} \quad$ Reflected strain wave

$\varepsilon_{\mathrm{e}} \quad$ Transmission Strain wave

$\eta \quad$ Efficiency

\section{References}

[1] C. Wang, Y. Han, S. Wang, Pressure control of rotary accumulator, Int. Conf. Fluid Power Mechatron. 14, 13951398 (2015)

[2] V.E. Geller, Characteristic features of necking during drawing and ultrahigh-speed spinning of polyethylene phthalate yarns, Review, Fibre Chem. 48, 1-11 (2016)

[3] Z.X. Li, X.D. Shu, Numerical and experimental analysis on multi-pass conventional spinning of the cylindrical part with GH3030, Int. J. Adv. Manuf. Technol. 103, 2893-2901 (2019)

[4] H. Wu, W.C. Xu, D.B. Shan, Mechanism of increasing spinnability by multi-pass spinning forming - Analysis of damage evolution using a modified GTN model, Int. J. Mech. Sci. 159, 1-19 (2019)

[5] B. Sun, J. Guo, Y. Lei, Simulation and verification of a nonequilibrium thermodynamic model for a steam catapult's steam accumulator, Int. J. Heat Mass Transf. 85, 88-97 (2015)

[6] R. Tomisawa, T. Ikaga, K.H. Kim, et al., Effect of melt spinning conditions on the fiber structure development of polyethylene terephthalate, Polymer 116, 367-377 (2016)

[7] Q.H. Su, F. Peng, J. Xing, Experimental research on advanced accumulator, Yuanzineng Kexue Jishu/At. Energy Sci. Technol. 51, 636-640 (2017)

[8] W. Latas, J. Stojek, A new type of hydrokinetic accumulator and its simulation in hydraulic lift with energy recovery system, Energy 153, 836-848 (2018)

[9] H. Kadakia, A. Baker, M. Paulsen, A mechanistic accumulator model for RETRAN-3D, Nucl. Technol. 202, 71-80 (2018)

[10] B. Ryszard, B. Zbigniew, H.S. Anna, Methodology and a continuous time mathematical model for selecting the optimum capacity of a heat accumulator integrated with a CHP plant, Energies 11, 1240 (2018)

[11] I. Victor, S.A. Casper, Hydraulic pitch control system for wind turbines: Advanced modeling and verification of an hydraulic accumulator, Simul. Model. Pract. Theory. 79, 1-22 (2017)

[12] S.M. Ostroumov, Choice and optimization of parameters of a transpiration cooling accumulator, Inzhenerno-Fizicheskii Zhurnal 60, 918-922 (1991)
[13] J. Lee, U.Y. Lee, Design optimization of an accumulator for reducing rotary compressor noise, Proc. Inst. Mech. Eng. 226, 285-296 (2012)

[14] J.Z. Hui, Y.K. Yang, H.Y. Zhang, Braking energy recovery system and control optimization of excavator based on accumulator, Chin. J. Highway Transp. 29, 143-151 (2016)

[15] M. Yu, B.Q. Shi, Optimization design and robust analysis of accumulator in hydraulic brake system, Nongye Gongcheng Xuebao/Trans. Chin. Soc. Agri. Eng. 27, 132-136 (2011)

[16] Q.D. Zhu, P. Lu, Z.B. Yang, Multi-parameter optimization for the wet steam accumulator of a steam-powered catapult, Energies 12, 234 (2019)

[17] A. Hashemi, M.H. Gollo, Application of a new integrated optimization approach in sheet hydroforming process, Mech. Ind. 19, 303 (2018)

[18] U.Y. Lee, B.J. Kim, J.B. Lee, Design optimization of an accumulator for noise reduction of rotary compressor, Trans. Korean Soc. Mech. Eng. 35, 759-766 (2011)

[19] Q.J. Chen, Z.X. Xu, X.H. Yue, Characteristic modeling and parameter optimization of the accumulator in hydraulic power take-off system for wave power generation, Yingyong Jichu yu Gongcheng Kexue Xuebao/J. Basic Sci. Eng. 27, 226-237 (2019)

[20] Y.C. Lin, S.S. Qian, X.M. Chen, Staggered spinning of thinwalled Hastelloy C-276 cylindrical parts: Numerical simulation and experimental investigation, Thin-Walled Struct. 140, 466-476 (2019)

[21] M. Li, Y.Y. Xu, H. Li, A novel spinning process for simultaneously producing two cone parts with big angle, J. Chin. Inst. Eng. 41, 547-556 (2018)

[22] S. Mohammad, J. Iraj, K.N. Mehdi, Experimental study and FEM analysis of forward hot dieless spinning, Mech. Ind. 19 404 (2018)

[23] T. Yoichi, K. Shigefumi, N. Takuo, Effects of neck length on occurrence of cracking in tube spinning, Proc. Manuf. 15, 1200-1206 (2018)

[24] W. Luo, F. Chan, B. Vu, et al. Study on compound spinning technology of large thin-walled parts with ring inner ribs and curvilinear generatrix, Int. J. Adv. Manuf. Technol. 98, 1199-1216 (2018)

[25] X. Zhiyong, R. Yuejuan, L. Wenbo, Effect of feed speed on aluminum alloy pipe neck-spinning process and deformation analysis via simulation, MATEC Web Conf. 67, 05011$05016(2016)$

[26] X. Zhanga, L. Zhaoa, T. Wena, An optimized neck-spinning method for improving the inner surface quality of titanium domes, Procedia Eng. 207, 1731-1736 (2017)

[27] K.R. Biplov, Y.P. Korkolis, A. Yoshio, Experiments and simulation of shape and thickness evolution in multi-pass tube spinning, J. Phys. Conf. Ser. 1063, 012087-012092 (2018)

[28] S.M. Ghoreishian, M. Norouzi, A. Fereydooni, Optimization of melt-spinning parameters of poly(ethylene terephthalate) partially oriented multi-filament yarn in an industrial scale: Central composite design approach, Fibers Polym. 18, 12801287 (2017)

[29] J.J. Cummins, S. Thomas, C.J. Nash, Experimental evaluation of the efficiency of a pneumatic strain energy accumulator, Int. J. Fluid Power. 18, 167-180 (2017)

[30] A. Kumar, J. Das, K. Dasgupta, et al., Effect of hydraulic accumulator on pressure surge of a hydrostatic transmission system, J. Inst. Eng. (India) Ser. C 99, 169-174 (2017) 
[31] J. Cai, K. Wang, P. Zhai, A modified Johnson-Cook constitutive formula to predict hot deformation behavior of Ti-6Al-4V alloy, J. Mater. Eng. Perf. 24, 32-44 (2015)

[32] L.Z. Zhou, L.M. Yang, Comparative study on constitutive models to predict flow stress of $\mathrm{Fe}-\mathrm{Cr}-\mathrm{Ni}$ preform reinforced Al-Si-Cu-Ni-Mg composite, J. Wuhan Univ. Technol. Mater. Sci. Ed. 32, 666-676 (2017)

[33] M. Alitavoli, A. Darvizeh, M. Moghaddam, Numerical modeling based on coupled Eulerian-Lagrangian approach and experimental investigation of water jet spot welding process, Thin-Walled Struct. 127, 617-628 (2018)

[34] X.-q. Chang, L.-y. Zhang, Y.-b. Yang, J.-l. Ren, Constitutive Models for Compressive Deformation of AZ80 Magnesium Alloy under Multiple Loading Directions and Strain Rates, J. Iron Steel Res. Int. 23, 64-68 (2016)

[35] D.-N. Zhang, Q.-Q. Shangguan, C.-J. Xie, F. Liu, A modified Johnson-Cook model of dynamic tensile behaviors for 7075-T6 aluminum alloy, J. Alloys Compd. 619, 186$194(2015)$

[36] M. Machorro-López José, A. Bellino, S. Marchesiello, Wavelets-based damage localization on beams under the influence of moving loads, Mechanics 14, 107-113 (2013)

[37] K. Erik, Meshing recommendations for the P-approach application in ABAQUS - A tool for pheno-numerical spring-in prediction, Compos. Struct. 203, 1-10 (2018)

[38] S.Q. Zhang, J.X. Yan, L. Cao, Crack Propagation Simulation of Hot Mill Grinding with Wood Based on ADAMS and ABAQUS, Linye Kexue/Scientia Silvae Sinicae. 54, 149-156 (2018)

[39] Z.R. Yang, X.L. Bai, Y.H. Xie, Finite element analysis on the collision between serial risers by using ABAQUS software, J. Vib. Shock 36, 196-200 (2017)

[40] X. Shi, P. Teixeira, J. Zhang, Kriging response surface reliability analysis of a ship-stiffened plate with initial imperfections, Struct. Infrastruct. Eng. 89, 1-16 (2014)
[41] X.L. Jia, J. Wang, Y.L. Zhang, True stress and shakedown analysis of pressure vessel under repeated internal pressure, Mech. Ind. 17, 410 (2016)

[42] C.N.C. Bhatra, S.A. Saheb, Note on reduction of dimensionality for second order response surface design model, Commun. Stat. Theory Methods 46, 3520-3525 (2016)

[43] R.K. Kamaraj, J.G. Thankachi Raghuvaran, A.F. Panimayam, Performance and exhaust emission optimization of a dual fuel engine by response surface methodology, Energies 11, 3508 (2018)

[44] W.S. Liu, X.M. Yao, C.Q. Li, Optimization of configuration parameters of tail-sitter UAV based on response surface and genetic algorithm, Trans. Chin. Soc. Agri. Mach. 50, 88-95 (2019)

[45] A. Caglar, T. Sahan, M.S. Cogenli, A novel central composite design based response surface methodology optimization study for the synthesis of $\mathrm{Pd} / \mathrm{CNT}$ direct formic acid fuel cell anode catalyst, Int. J. Hydrogen Energy 43, 11002-11011 (2018)

[46] C. Lu, L. Gao, X. Li, Energy-efficient multi-pass turning operation using multi-objective backtracking search algorithm, J. Clean. Prod. 137, 1516-1531 (2016)

[47] M.A. Sahali, I. Belaidi, R. Serra, New approach for robust multi-objective optimization of turning parameters using probabilistic genetic algorithm, Int. J. Adv. Manuf. Technol. 83, 1265-1279 (2016)

[48] J. Song, J. Li, Q.H. Yang, Multi-objective optimization and its application on irrigation scheduling based on AquaCrop and NSGA-II, J. Hydraulic Eng. 49, 1284-1295 (2018)

[49] J. Huang, Z.B. Chen, Q.M. Liu, Multi-objective optimization for laser closure process parameters in vitro skin tissue based on NSGA-II, Chin. J. Lasers 46, 0207001 (2019)

[50] L.B. Huo, Z.Q. Cao, F. Zhang, Numerical and experimental study on TC4-DT titanium alloy structure after double cold expansion, J. Northwest. Polytech. Univ. 36, 701-708 (2018)

Cite this article as: B. Li, Y. Li, P. Zhu, W. Ma, Y. Xiao, X. Li, Study on optimization of thermal spinning process of accumulator shell, Mechanics \& Industry 21, 402 (2020) 